Check for updates

Cite this: Mater. Chem. Front., 2019, 3, 922

Received 30th January 2019, Accepted 28th March 2019

DOI: $10.1039 / \mathrm{c} 9 q m 00057 \mathrm{~g}$

rsc.li/frontiers-materials

\title{
Janus hollow polymeric hairy microspheres as efficient adsorbents and catalyst scaffolds $\uparrow$
}

\author{
Guang Wu, ${ }^{a}$ Lingling Zhao, (D) *ab Hongze Liang, ${ }^{a}$ Yinghua Yan (D) $^{a}$ and Hui Tan ${ }^{b}$
}

Polymeric hairy microspheres with a Janus hollow structure were prepared via cationic polymerization using $\mathrm{SiO}_{2}$ nanoparticles as interface protection cores and sacrificial templates. Sulfonic acid groups $\left(-\mathrm{SO}_{3} \mathrm{H}\right)$ were introduced onto the surface of the microspheres by sulfonation and facilitated the further loading of titania. The Janus hollow polymeric hairy microspheres (HSPHS) could be applied as efficient adsorbents to remove both hydrophilic dye rhodamine B (RB) and hydrophobic dye dimethyl yellow (DMY) from the surrounding solution, and the results showed that $>98 \%$ of RB or/and DMY could be removed within several minutes. The maximum adsorption amount on the Janus HSPHS was 3.48 and $0.14 \mathrm{~mol} \mathrm{~g}^{-1}$ for RB and DMY, respectively. In addition, the HSPHS can also serve as catalyst scaffolds to load anatase titania for the photocatalytic degradation of RB. Janus hollow microspheres coated with anatase titania ( $\mathrm{HSPHS}\left(\mathrm{ATiO}_{2}-\mathrm{An}\right.$ ) demonstrated a remarkable photocatalytic efficiency and recyclability. High photocatalytic activity was observed for $\mathrm{HSPHSCTiO}_{2}$-An and the catalytic efficiency remained with almost no loss of the photocatalytic activity even after five catalytic cycles. Thus, the Janus hollow polymeric hairy microspheres have promising applications in water treatment as efficient adsorbents and catalyst scaffolds.

\section{Introduction}

Nowadays, with the increased development of industrialization and technology, water pollution caused by a large amount of wastewater discharged from factories has a serious influence on the environment and human health. ${ }^{1,2}$ As organic dyes widely used in the paper, textile, coating, dying, printing and related industries are one of the most common contaminations in wastewater responsible for pollution problems, the removal of dyes from wastewater is required for environmental protection. ${ }^{3,4}$ Therefore, various treatment technologies including biological (aerobic processes, anaerobic processes and combined aerobic-anaerobic processes), ${ }^{5-7}$ chemical (electrochemical or advanced oxidation, photo-catalysis or sonolysis $)^{8,9}$ and physical (membrane separation and adsorption) $)^{10,11}$ methods have been explored to remove dyes from wastewater. Among these methods, adsorption and catalysis techniques have attracted much

\footnotetext{
${ }^{a}$ School of Materials Science and Chemical Engineering, Ningbo University, Ningbo, 315211, China.E-mail: zhaolingling@nbu.edu.cn

${ }^{b}$ Health Science Center, The First Affiliated Hospital of Shenzhen University, Shenzhen, 518035, China. E-mail: huitan@email.szu.edu.cn

$\dagger$ Electronic supplementary information (ESI) available: Synthetic conditions of $\mathrm{SiO}_{2} @ P H S, \mathrm{SiO}_{2} @ S P H S$ and HSPHS; FT-IR spectra; EDX spectra; adsorption kinetics of RB with HSPHS; adsorption percentage of RB with HSPHS; adsorption kinetics of DMY with HSPHS; adsorption percentage of DMY with HSPHS; photocatalytic degradative capacity of RB. See DOI: $10.1039 / \mathrm{c} 9 \mathrm{qm} 00057 \mathrm{~g}$
}

attention due to their high efficiency, convenient operation and cost-effectiveness. ${ }^{12,13}$

A number of adsorbents have been applied to remove dyes from wastewater. For example, low-cost adsorbents produced on the basis of agricultural wastes, natural compounds and activated carbon have been used to remove pollutants indiscriminately, ${ }^{14-17}$ while their adsorption capacities, mechanical strength and other properties need further improvement. ${ }^{18}$ Many conventional porous materials such as activated carbon, ${ }^{19-21}$ zeolites $^{22,23}$ and nanotubes ${ }^{24,25}$ have been extensively used to adsorb pollutants for water cleaning, while they have the disadvantages of low adsorption capacity and removal efficiency. ${ }^{26}$ Due to the high surface area, good mechanical strength, adjustable surface chemistry and easy regeneration, polymeric adsorbents are potential candidates to remove different pollutants from aqueous media, and the adsorption capacity of polymeric adsorbents could be improved by using functional monomers to bound target pollutants with the polymeric matrix via specific interactions. ${ }^{18,27}$ In recent years, covalently linked porous polymers such as conjugated nano-/mircoporous polymers, ${ }^{28,29}$ covalent organic frameworks, ${ }^{30}$ hyper cross-linked polymers $^{31,32}$ and synthetic functional copolymers ${ }^{33,34}$ have aroused much attention and been successfully applied in adsorption due to their vast surface area, low density and feasible functionality.

In addition, porous polymeric microspheres with high specific surface areas and physicochemical stability are attractive adsorbents in the application of water treatment. 
Yao and coworkers ${ }^{35}$ reported porous magnetic polyacrylamide microspheres for efficient removal of methylene blue with high adsorption efficiency and capacity. The adsorbed dyes can be easily desorbed from the magnetic polyacrylamide microspheres, and the polymeric microsphere adsorbents can be repeatedly used for at least 6 cycles without losing the adsorption capacity. Chen et $a l^{36}$ designed and fabricated novel dualfunctionalized hollow polymer particles (DF-HPP) as a highperformance adsorbent for selective removal of methylene blue. The DF-HPPs exhibited excellent adsorption properties with high adsorption capacity, fast adsorption/desorption rates, unique $\mathrm{pH}$-sensitivity and easy recovery due to the high density of carboxylate and amino groups as well as the high surface area.

Apart from being good adsorbent candidates, porous polymeric microspheres can also serve as catalyst scaffolds and have gained extensive attention in the past few decades. ${ }^{12,37}$ Wang et $a .^{38}$ fabricated novel chitin microspheres as the enabling platform for a range of applications including as a recyclable catalyst support and adsorbent. The swollen porous polymer could successfully control the growth of gold nanoparticles and reduced the dimensions of metal particles $(r \leq 5 \mathrm{~nm})$. The chitin/Au nanocomposite microspheres served as adsorbents for enhanced removal of methylene blue from aqueous solution. Yang et al..$^{39}$ prepared porous poly(styrenedivinylbenzene) microspheres with an interconnected structure for effective adsorption of dyes in an aqueous solution, and the Ag-loaded hybrid microspheres exhibited excellent catalytic degradation of the dyes. Very recently, hierarchical porous spheres with a special structure have attracted another wave of interest in the fabrication of functional materials because of their functional properties. ${ }^{40,41}$ Ning et al. ${ }^{12}$ developed a novel kind of polymeric microsphere with a hierarchical porous structure (HPPMs) based on double Pickering emulsion templates. The HPPMs can be employed as an effective adsorbent for rhodamine 6G. The hierarchical porous structure of the HPPMs can offer loading sites for Ag particles as well as protect the $\mathrm{Ag}$ particles from aggregation. Thus, the noble metal loaded HPPMs maintained an outstanding performance in catalysis and recyclability.

Herein, we developed a novel kind of polymeric hairy microsphere with a Janus hollow structure via cationic polymerization using $\mathrm{SiO}_{2}$ nanoparticles as the interface protection cores and sacrificial templates, in which the interior cavity was hydrophobic and the exterior surface was hydrophilic and connected with polymeric tubular fibers. Sulfonic acid groups were introduced into the exterior surface of the microspheres by sulfonation and facilitated the further loading of titania; thus, the Janus hollow polymeric hairy microspheres can serve as efficient adsorbents as well as catalyst scaffolds. So far, most of the reported adsorbents for water cleaning can remove the basic or cationic dyes from wastewater, ${ }^{19,42}$ such as methyl blue basic yellow 21, basic red 22, Congo red, rhodamine B and rhodamine $6 \mathrm{G}$, and these synthetic organic dyes are water soluble dyes. However, the contaminating dyes discharged from factories into water include not only water-soluble (hydrophilic) dyes but also water-insoluble (hydrophobic) dyes. ${ }^{15}$
Therefore, the removal of both hydrophilic and hydrophobic dyes from wastewater is of great importance for water cleaning and environment protection. The novel Janus hollow polymeric hairy microspheres with a hydrophobic interior cavity and a hydrophilic surface can remove both hydrophilic and hydrophobic dyes from wastewater, and the further loaded titania can serve as a photocatalyst to degrade the contaminated dyes in the wastewater. In this work, the fabrication and characterization of Janus hollow polymeric hairy microspheres were demonstrated and the adsorption and catalytic properties were evaluated.

\section{Experimental}

\section{Materials}

Divinylbenzene (80\%) (DVB) and hydrofluoric acid (40\%) (HF) were purchased from Aladdin Reagent Company. Boron trifluoride diethyl etherate complex $\left(\mathrm{BF}_{3} \cdot \mathrm{O}(\mathrm{Et})_{2}\right)$ was purchased from TCL (Shanghai) Development Co, Ltd. Tetraethyl orthosilicate (TEOS), dimethyl yellow (DMY), alkaline alumina, concentrated sulfuric acid $\left(\mathrm{H}_{2} \mathrm{SO}_{4}, 95-98 \%\right)$, ammonium hydroxide $\left(\mathrm{NH}_{3} \cdot \mathrm{H}_{2} \mathrm{O}\right.$, $28 \%$ ), span 80 , anhydrous ethanol and $n$-hexane were purchased from Sinopharm Group Chemical Reagent Co., Ltd, China. Tetrabutyl titanate (TBOT) was purchased from Shanghai Macklin Biochemical Co., Ltd, China. Rhodamine B (RB) was purchased from Shanghai Yuanye Biochemical Co., Ltd, China.

\section{Preparation of the $\mathrm{SiO}_{2}$ cores}

$\mathrm{SiO}_{2}$ nanospheres with the diameter of $400 \mathrm{~nm}$ were synthesized by the alkaline hydrolysis of TEOS via the well-know Stöber method. Briefly, $40 \mathrm{~mL}$ of anhydrous ethanol, $2.7 \mathrm{~mL}$ of deionized water and $4 \mathrm{~mL}$ of ammonium hydroxide were added to a flask in sequence under room temperature. The mixture was stirred for $20 \mathrm{~min}$ to form a uniform solution and then $3.3 \mathrm{~mL}$ of TEOS was added and stirred for another $6 \mathrm{~h}$ at room temperature. The precipitate was centrifuged and washed

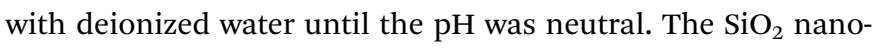
spheres were dried at $60{ }^{\circ} \mathrm{C}$ and stored at room temperature for further use.

\section{Preparation of $\mathrm{SiO}_{2} @$ polymeric hairy spheres ( $\left.\mathrm{SiO}_{2} @ \mathrm{PHS}\right)$}

$\mathrm{SiO}_{2} @$ @PHS was produced by polymerization of the DVB on the surface of the $\mathrm{SiO}_{2}$ cores. The DVB was filtered with alkaline alumina to remove the inhibitor before use. Typically, $10 \mathrm{mg}$ of $\mathrm{SiO}_{2}$ nanospheres were dispersed ultrasonically in $50 \mathrm{~mL}$ of $n$-hexane in a $100 \mathrm{~mL}$ flask. $59 \mathrm{mg}$ of span 80 was added to the dispersion and mixed uniformly. Then, $54 \mu \mathrm{L}$ of $\mathrm{BF}_{3} \cdot \mathrm{Et}_{2} \mathrm{O}$ was added and the mixture gradually turned yellow. Next, $550 \mu \mathrm{L}$ of DVB was added to react for several minutes and then anhydrous ethanol was added to quench the reaction. A white precipitate was generated at the bottom of the flask. The product was washed with ethanol three times and dried at room temperature. $\mathrm{SiO}_{2} @ \mathrm{PHS}$ with different morphologies could be obtained by changing the feed ratio of span $80, \mathrm{BF}_{3} \cdot \mathrm{Et}_{2} \mathrm{O}$ and DVB as well as the reaction time. 
Preparation of $\mathrm{SiO}_{2} @$ @sulfonated polymeric hairy spheres ( $\left.\mathrm{SiO}_{2} @ \mathrm{SPHS}\right)$

$\mathrm{SiO}_{2} @ S P H S$ was achieved by the following process. $400 \mathrm{mg}$ of $\mathrm{SiO}_{2} @ P H S$ was dispersed into $10 \mathrm{~mL}$ of concentrated sulfuric acid at room temperature for several hours; next, the microspheres were washed with a large amount of ethanol and deionized water to remove the sulfuric acid and then dried at $60{ }^{\circ} \mathrm{C}$. The harvested light yellow product was stored at room temperature for further use.

\section{Preparation of Janus hollow sulfonated polymeric hairy spheres (HSPHS)}

HSPHS was produced by etching the $\mathrm{SiO}_{2}$ cores of $\mathrm{SiO}_{2} @ \mathrm{SPHS}$ with HF. Typically, $150 \mathrm{mg}$ of $\mathrm{SiO}_{2} @ S P H S$ with different sulfonated times was dispersed in $4 \mathrm{~mL}$ of $\mathrm{HF}(2 \%)$ and ultrasonicated for $4 \mathrm{~min}$. Then, the reaction was terminated with ammonia and the polymeric spheres were washed several times with deionized water and then dried at $60{ }^{\circ} \mathrm{C}$. The harvested light yellow product was stored at room temperature for further use.

\section{Preparation of titania encapsulated HSPHS (HSPHS@TiO ${ }_{2}$ )}

Encapsulation of the HSPHS with titania was performed according to previously reported work. ${ }^{43} 1.5 \mathrm{~mL}$ of TВОТ was dispersed in $10 \mathrm{~mL}$ of anhydrous ethanol, and then the mixture was added dropwise into $10 \mathrm{~mL}$ of ethanol suspension containing $50 \mathrm{mg}$ of HSPHS-3 under stirring. $2 \mathrm{~mL}$ of distilled water was dropped into the mixture and stirred for another $6 \mathrm{~h}$. The microspheres were washed several times with ethanol and deionized water and then dried at room temperature. The sample was coded as HSPHS@TiO ${ }_{2}$-Am. The crystallization treatment of the as-prepared amorphous titania was performed by the hydrothermal method. ${ }^{44} 50 \mathrm{mg}$ of $\mathrm{HSPHS} @ \mathrm{TiO}_{2}$-Am was added to a Teflon-lined autoclave with $20 \mathrm{~mL}$ of deionized water, and the autoclave was sealed and placed in an oven at $180{ }^{\circ} \mathrm{C}$ for $2 \mathrm{~h}$. After cooling down to room temperature, the microspheres were centrifuged and washed with deionized water, and then dried at

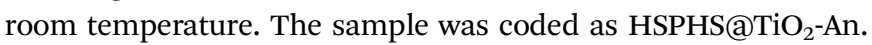

\section{Characterization}

Scanning electron microscopy (SEM, FEI Nova NanoSEM 450, $5 \mathrm{kV}$ ) and transmission electron microscopy (TEM, JEOL JEM2100, $200 \mathrm{kV}$ ) were conducted to observe the morphology of the samples. The surface composition of the microspheres was tested using energy-dispersive X-ray spectroscopy (EDX) on SEM. Infrared absorption spectra of the samples were measured using a Nicolet 6700 spectrometer with the sample/KBr pressed pellets. The XRD pattern was collected using a Bruker D8 Focus X-ray diffractometer. Thermogravimetric analysis was performed on a TG/DTA (Diamond, PerkinElmer) with a heating rate of $10{ }^{\circ} \mathrm{C} \mathrm{min}{ }^{-1}$ from room temperature to $800{ }^{\circ} \mathrm{C}$ under an air atmosphere.

The Janus character of the HSPHS was characterized using a confocal laser scanning microscope (CLSM, Olympus FV1000). The HSPHS was dispersed in the aqueous solution of RB $\left(50 \mathrm{mg} \mathrm{L}^{-1}\right)$ for $10 \mathrm{~min}$ to achieve saturation adsorption. The HSPHS was collected via centrifugation and re-dispersed in water. A drop of HSPHS aqueous dispersion was dropped onto a microscope slide and covered with a coverslip. The slides were observed under CLSM with an excitation wavelength of $488 \mathrm{~nm}$ and an emission wavelength range of $510-600 \mathrm{~nm}$.

\section{Adsorption abilities of HSPHS}

Adsorption of hydrophilic dyes using HSPHS. RB, a hydrophilic dye, was selected as a model compound for the adsorption test. $5 \mathrm{mg}$ of the HSPHS was dispersed in $20 \mathrm{~mL}$ of RB aqueous solution $\left(50 \mathrm{mg} \mathrm{L}^{-1}\right)$ and then the mixture was divided into five equal parts and incubated at room temperature to allow dye adsorption. At a predicted time, the supernatant was centrifuged, collected and measured using UV-visible spectroscopy (TU-1901).

The adsorption isotherms were obtained by batch equilibrium experiments. In detail, a series of $1 \mathrm{mg}$ of HSPHS was dispersed in $4 \mathrm{~mL}$ of $\mathrm{RB}$ solution with concentrations ranging from 10 to $800 \mathrm{mg} \mathrm{L}^{-1}$, respectively. The dispersion was centrifuged after incubating at room temperature for $10 \mathrm{~min}$. The supernatant was collected and measured using UV-visible spectroscopy (TU-1901) to determine the residual dye concentration. The amounts of the adsorbed $\mathrm{RB}$ were calculated using the following equation: $Q_{\mathrm{e}}=\left(C_{0}-C_{\mathrm{e}}\right) \times \mathrm{V} / \mathrm{m}$, where $C_{0}$ is the initial concentration of $\mathrm{RB} ; C_{\mathrm{e}}$ is the equilibrium concentration after adsorption; $V$ is the solution volume and $m$ is the mass of HSPHS. Photos were taken before and after adsorption.

Adsorption of hydrophobic dyes using HSPHS. DMY, a hydrophobic dye, was selected as a model compound for the adsorption test. $5 \mathrm{mg}$ of the HSPHS was dispersed in $5 \mathrm{~mL}$ of deionized water, and then the dispersion was divided into five equal parts and each part was added into $1 \mathrm{~mL}$ of DMY hexane solution $\left(20 \mathrm{mg} \mathrm{L}^{-1}\right)$. The mixture was ultrasonically shaken at room temperature and then held for equilibrated phase separation. At the predicted time, the hexane supernatant was centrifuged, collected and measured using UV-visible spectroscopy (TU-1901).

The adsorption isotherms were obtained by batch equilibrium experiments. A series of $1 \mathrm{~mL}$ of HSPHS aqueous dispersions $\left(1 \mathrm{mg} \mathrm{mL}^{-1}\right)$ was added into $1 \mathrm{~mL}$ of DMY hexane solution with concentrations ranging from 5 to $50 \mathrm{mg} \mathrm{L}^{-1}$, respectively. The mixture was ultrasonically shaken for $10 \mathrm{~min}$ and held for equilibrated phase separation. The hexane supernatant was centrifuged, collected and measured using UV-visible spectroscopy (TU-1901) to determine the residual dye concentration. The amounts of the adsorbed DMY were calculated using the following equation: $Q_{\mathrm{e}}=\left(C_{0}-C_{\mathrm{e}}\right) \times \mathrm{V} / \mathrm{m}$, where $C_{0}$ is the initial concentration of the DMY hexane solution; $C_{\mathrm{e}}$ is the equilibrium concentration of the DMY hexane solution after phase transfer; $V$ is the solution volume of hexane and $m$ is the mass of HSPHS. Photos were taken before and after adsorption.

Adsorption of hydrophilic and hydrophobic dyes simultaneously using HSPHS. $4 \mathrm{mg}$ of HSPHS was added into $4 \mathrm{~mL}$ of an ethanol solution containing $20 \mathrm{mg} \mathrm{L}^{-1}$ DMY and $80 \mathrm{mg} \mathrm{L}^{-1}$ RB. The mixture was incubated at room temperature. At the predicted time, the supernatant was centrifuged, collected and 
measured using UV-visible spectroscopy (TU-1901). Photos were taken before and after adsorption.

\section{Catalytic properties of HSPHS@TiO}

Photocatalytic degradation kinetics. $7 \mathrm{mg}$ of HSPHS-3, HSPHS@TiO ${ }_{2}$-Am and HSPHS@TiO ${ }_{2}$-An was dispersed in an aqueous solution of $\mathrm{RB}\left(50 \mathrm{mg} \mathrm{\textrm {L } ^ { - 1 }}\right)$ for $10 \mathrm{~min}$ to achieve saturation adsorption, respectively. The microspheres were centrifuged, collected and washed with water, and then re-dispersed in $0.7 \mathrm{~mL}$ of deionized water, respectively. Then, a series of $0.1 \mathrm{~mL}$ of microsphere aqueous dispersions $\left(10 \mathrm{mg} \mathrm{mL}^{-1}\right)$ was added into $4 \mathrm{~mL}$ of $\mathrm{RB}$ aqueous solution ( 50 or $300 \mathrm{mg} \mathrm{L}^{-1}$ ), respectively. The mixture was irradiated using a UV light $(30 \mathrm{~W}, 254 \mathrm{~nm})$ under stirring for photocatalytic degradation of the dye. At the predicted time, the supernatant was centrifuged, collected and measured using UV-visible spectroscopy (TU-1901). The kinetics of photocatalytic decolorization of the $\mathrm{RB}$ aqueous solution was expressed as $\ln \left(C_{0} / C\right)=k t$, where $k$ is the apparent rate constant, $C_{0}$ is the initial concentration of $\mathrm{RB}$ and $C$ is the concentration after UV irradiation. ${ }^{44}$

Photocatalytic degradation capacity. $8 \mathrm{mg}$ of HSPHS-3, HSPHS@TiO ${ }_{2}$-Am and HSPHS@TiO ${ }_{2}$-An were dispersed in the aqueous solution of $\mathrm{RB}\left(50 \mathrm{mg} \mathrm{\textrm {L } ^ { - 1 }}\right)$ for $10 \mathrm{~min}$ to achieve saturation adsorption, respectively. The microspheres were centrifuged, collected and washed with water, and then redispersed in $0.8 \mathrm{~mL}$ deionized water, respectively. Then, a series of $0.1 \mathrm{~mL}$ of microsphere aqueous dispersions $\left(10 \mathrm{mg} \mathrm{mL}^{-1}\right)$ was added into $4 \mathrm{~mL}$ of $\mathrm{RB}$ aqueous solution with concentrations ranging from 10 to $400 \mathrm{mg} \mathrm{L}^{-1}$, respectively. The mixture was irradiated using a UV light ( $30 \mathrm{~W}, 254 \mathrm{~nm})$ under stirring for $5 \mathrm{~h}$. $\mathrm{RB}$ solution at the same concentration without any microspheres was used as a control. The supernatant was centrifuged, collected and measured using UV-visible spectroscopy (TU-1901). The amount of photodegradative RB was calculated using the following equation: De $=\left(C_{0}-C_{t}\right) \times V$, where $C_{0}$ is the initial concentration of $\mathrm{RB}$; $C_{t}$ is the concentration after $\mathrm{UV}$ irradiation; $V$ is the solution volume.

Regeneration of HSPHS@TiO ${ }_{2}$-An. 1 mg of HSPHS@TiO ${ }_{2}$-An was dispersed in an aqueous solution of $\mathrm{RB}\left(50 \mathrm{mg} \mathrm{L}^{-1}\right)$ for $10 \mathrm{~min}$ to achieve saturation adsorption. The microspheres were centrifuged, collected and washed with water, and then re-dispersed in $4 \mathrm{~mL}$ of $\mathrm{RB}$ aqueous solution $\left(50 \mathrm{mg} \mathrm{L}^{-1}\right)$. The mixture was irradiated using a UV light (30 W, $254 \mathrm{~nm})$ under stirring for $5 \mathrm{~h}$. Then, the supernatant was centrifuged, collected and measured using UV-visible spectroscopy (TU-1901). The precipitate was re-dispersed in $4 \mathrm{~mL}$ of fresh $\mathrm{RB}$ aqueous solution (50 $\mathrm{mg} \mathrm{L}^{-1}$ ) and the same procedure was followed. The experiment was performed for five cycles.

\section{Results and discussion}

Preparation and characterization of $\mathrm{SiO}_{2} @ \mathrm{PHS}$

$\mathrm{SiO}_{2} @ \mathrm{PHS}$ was prepared through a cationic polymerization initiated on the surface of $\mathrm{SiO}_{2}$ cores. $\mathrm{SiO}_{2}$ @PHS with various morphologies can be obtained by changing the preparation

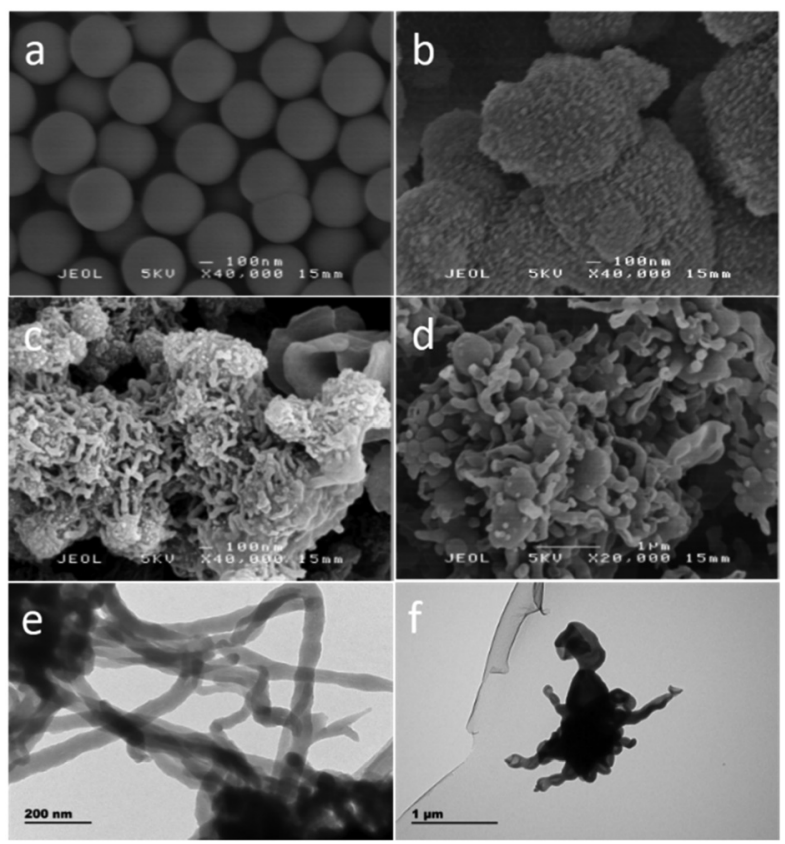

Fig. 1 SEM and TEM images of $\mathrm{SiO}_{2}$ nanoparticles (a), $\mathrm{SiO}_{2}(\mathrm{aPHS}-1$ (b), $\mathrm{SiO}_{2} @ \mathrm{aPHS}-2$ (c and e) and $\mathrm{SiO}_{2}(\mathrm{PPHS}-3$ (d and f).

parameters (Table S1, ESI $\dagger$ ). As shown in Fig. 1, the length of polymer fibers on the $\mathrm{SiO}_{2} @ \mathrm{PHS}$ surface increased as the polymerization time prolonged. After $1 \mathrm{~min}$ of polymerization, $\mathrm{SiO}_{2} @ P H S$ with a very coarse surface containing short fibers was observed ( $\mathrm{SiO}_{2} @ P H S-1$, Fig. 1b). When the polymerization time increased to $8 \mathrm{~min}$, hairy $\mathrm{SiO}_{2} @ \mathrm{PHS}$ with longer fibers on the surface was obtained $\left(\mathrm{SiO}_{2} @ \mathrm{PHS}-2\right.$, Fig. 1c). The TEM image of the hairy part showed that the polymeric fiber has a bamboo-like structure and a diameter of $\sim 60 \mathrm{~nm}$ (Fig. 1e). When increasing the amount of initiator and keeping the other parameters constant, anthoid $\mathrm{SiO}_{2} @ P H S$ with stumpy fibers on the surface was obtained ( $\mathrm{SiO}_{2} @$ PHS-3, Fig. 1d). TEM showed that the fiber part has a hollow structure and a diameter of $\sim 150 \mathrm{~nm}$ (Fig. 1f).

\section{Preparation and characterization of $\mathrm{SiO}_{2} @ S P H S$ and HSPHS}

$\mathrm{SiO}_{2}$ @PHS was sulfonated to introduce sulfonic acid groups $\left(-\mathrm{SO}_{3} \mathrm{H}\right)$ on the surface of the microspheres and harvested a hydrophilic exterior layer in the polymeric hairy spheres. The interior surface of the polymeric hairy spheres was protected from sulfonation by the $\mathrm{SiO}_{2}$ cores and resulted in a hydrophobic layer, thus the Janus shell was achieved. Subsequently, the $\mathrm{SiO}_{2}$ cores were etched using $\mathrm{HF}$ to get Janus hollow

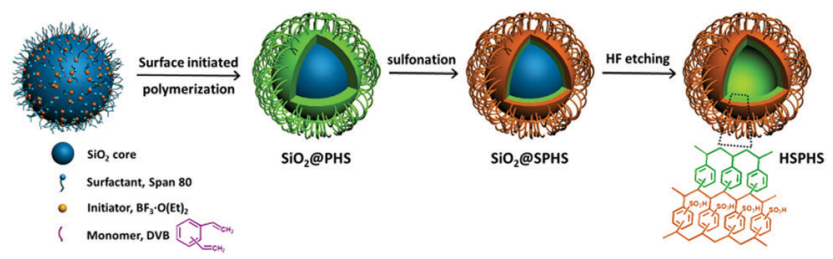

Scheme 1 Illustrative synthesis of the HSPHS. 


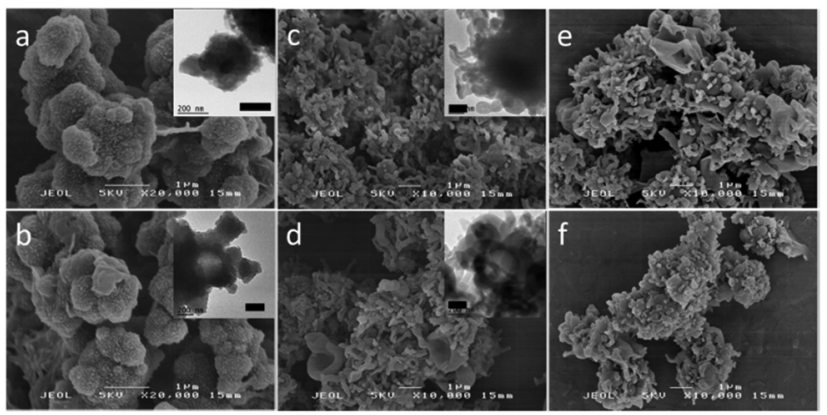

Fig. 2 SEM images of $\mathrm{SiO}_{2}$ (aSPHS and HSPHS. SiO $\mathrm{CSPHS}_{2}-1$ (a), HSPHS-4 (b), $\mathrm{SiO}_{2} \mathrm{QSPHS}-2$ (c), HSPHS-2 (d), $\mathrm{SiO}_{2} \mathrm{QSPHS}-3$ (e) and HSPHS-3 (f). Insets are TEM images, bar $=200 \mathrm{~nm}$.

polymeric hairy spheres, as shown in Scheme 1. In comparison with the $\mathrm{SiO}_{2} @ \mathrm{PHS}$, new peaks at 1175 and $1025 \mathrm{~cm}^{-1}$ appear in the FTIR spectrum of $\mathrm{SiO}_{2} @ S P H S$ (Fig. S1, ESI $\dagger$ ), confirming that $-\mathrm{SO}_{3} \mathrm{H}$ was successfully introduced to the polymeric hairy spheres. ${ }^{45}$ The SEM images showed that the morphology of the polymeric hairy spheres has no significant change before and after sulfonation or HF etching, and the hollow structure was observed under TEM after the $\mathrm{SiO}_{2}$ cores were removed by $\mathrm{HF}$ (Fig. 2). The Janus HSPHS indicated a ring-shaped fluorescent image under confocal laser scanning microscopy (CLSM) (Fig. 3a) when using water-soluble $\mathrm{RB}$ dye as a detector. This suggested that the RB molecules are selectively adsorbed onto the exterior surface because of the sulfonic acid groups. As a control, hollow polymeric hairy spheres prepared by first etching and then sulfonation were used to confirm the Janus shell. The CLSM displayed a sphereshaped fluorescence image (Fig. 3b) when incubated with RB, indicating that the whole cavity of the hollow polymeric hairy spheres was hydrophilic without the protection of the $\mathrm{SiO}_{2}$ cores.

\section{Preparation and characterization of HSPHS@TiO}

The introduction of $-\mathrm{SO}_{3} \mathrm{H}$ on the polymeric spheres' surface facilitated the loading of titania. The SEM images of the
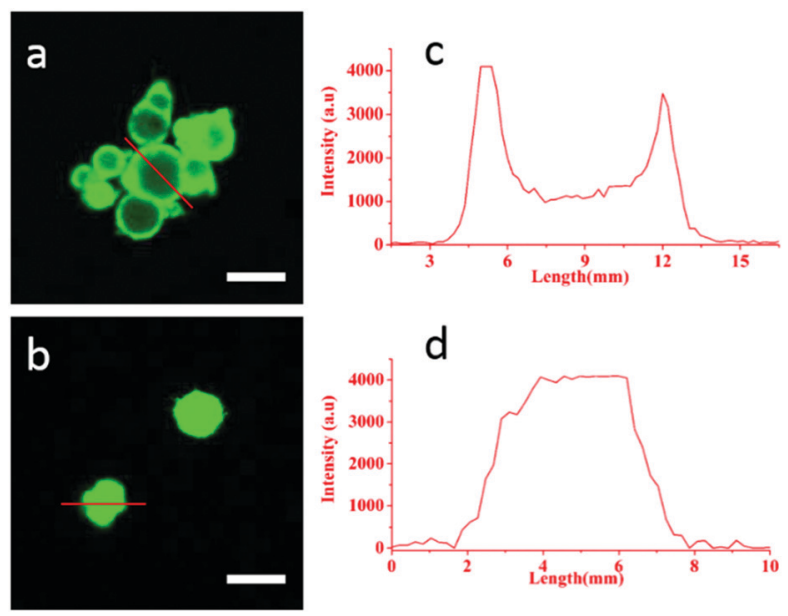

Fig. 3 CLSM images and the corresponding fluorescence intensity contours of the hollow polymeric hairy microspheres with (a and c) or without (b and d) Janus properties when incubated with RB. Bar $=2 \mu \mathrm{m}$.
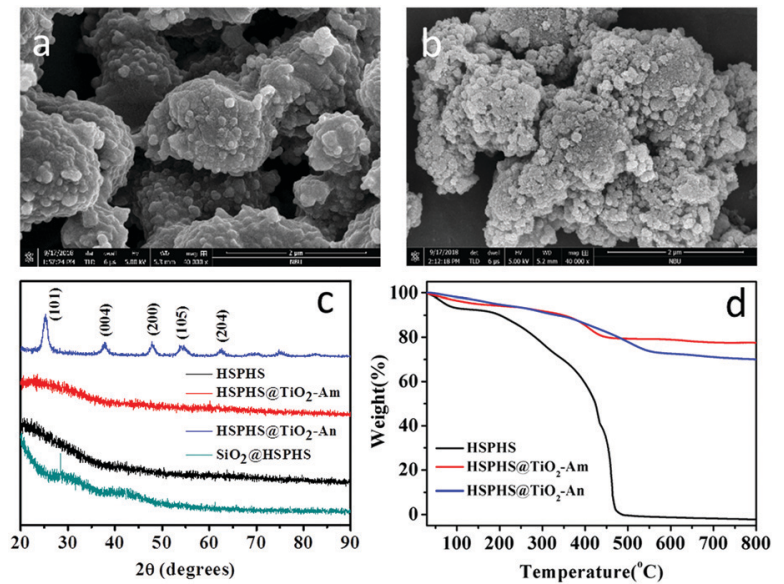

Fig. 4 The SEM images of $\mathrm{HSPHS} \mathrm{TTiO}_{2}-\mathrm{Am}(\mathrm{a})$ and $\mathrm{HSPHS}_{\mathrm{STiO}}-\mathrm{An}(\mathrm{b})$, the XRD spectra of $\mathrm{SiO}_{2}$ @SPHS, HSPHS, HSPHSCTiO - -Am and $\mathrm{HSPHSCTiO}_{2}-\mathrm{An}$ (c), and the TGA analysis of HSPHS and HSPHSATiO ${ }_{2}$ (d).

HSPHS@TiO ${ }_{2}$ showed that the $\mathrm{TiO}_{2}$ nanoparticles were coated onto the surface of the polymeric spheres and displayed coarse surfaces (Fig. 4). In comparison with the HSPHS, the HSPHS@ $\mathrm{TiO}_{2}$ displayed a new peak assigned to Ti in the EDX spectra (Fig. S2, ESI $\dagger$ ), confirming the successful loading of titania. The XRD spectra showed that the as-prepared (or untreated) titania has an amorphous state and the titania could transfer to anatase type through hydrothermal treatment. As shown in Fig. 4c, the diffraction peaks at $2 \theta$ angles of 25.3, $37.9,48.1,54.5$ and $62.7^{\circ}$ could be assigned to those of the anatase $\mathrm{TiO}_{2}$, reflecting (101), (004), (200), (105) and (204) crystalline planes (JCPDS No. 21-1272), respectively. ${ }^{4,46}$ The TGA analysis demonstrated that the content of titania loaded in

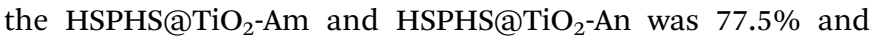
$70.0 \%$, respectively (Fig. 4d).

\section{Adsorption behavior of HSPHS}

The exterior layer of the Janus HSPHS was sulfonated to endow them with sulfonic acid groups, which could adjust the amphipathicity and adsorb water-soluble molecules. Rhodamine B (RB), a cationic dye used in the chemical industry but harmful to human health, was selected as a model compound to evaluate the adsorption ability of the Janus HSPHS. The adsorption isotherms for RB on different Janus HSPHS were displayed by the Langmuir model, where the amount of equilibrium adsorption, $Q_{\mathrm{e}}$, was plotted as a function of the equilibrium concentration in bulk solution, $C_{\mathrm{e}}$. The results demonstrated that the morphology and sulfonation degree of the Janus HSPHS had an effect on the dye adsorption. As shown in Fig. 5a, the anthoid Janus HSPHS with stumpy fibers on the surface (HSPHS-2) showed a higher adsorption capacity than the hairy Janus HSPHS when the sulfonation time was the same $(1 \mathrm{~h})$, and the hairy Janus HSPHS with longer fibers on the surface (HSPHS-1) displayed a higher adsorption capacity than the Janus HSPHS with short fibers on the surface (HSPHS-4). The adsorption of RB on the Janus HSPHS can be described by the Langmuir equation: $Q_{\mathrm{e}}=Q_{\max } K C_{\mathrm{e}} /\left(1+K C_{\mathrm{e}}\right),{ }^{47-49}$ where 

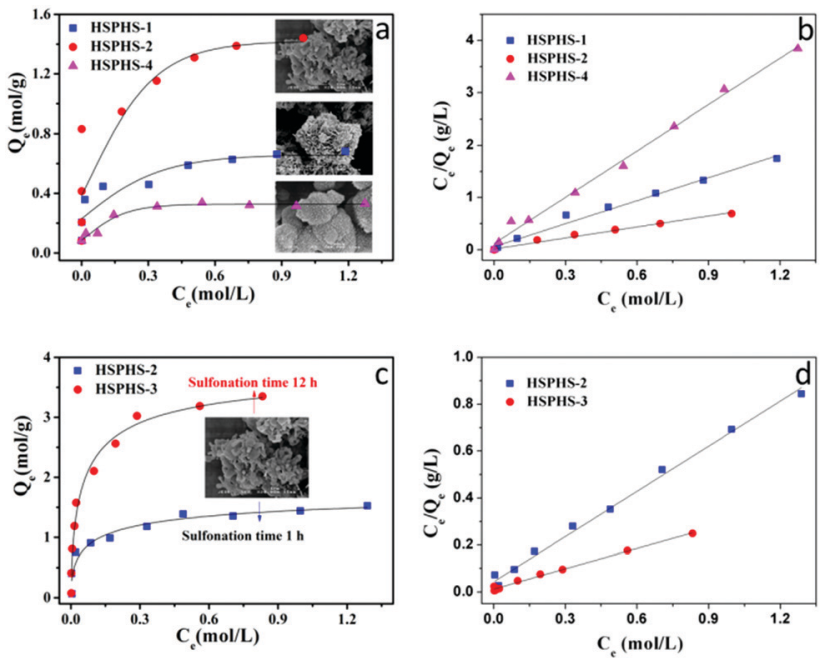

Fig. 5 The adsorption isotherms ( $a$ and $\mathrm{c}$ ) of RB and the corresponding linear plots ( $b$ and $d$ ) using the Janus HSPHS with different morphologies (polymeric hairy) and sulfonation time at room temperature, respectively (HSPHS: $1 \mathrm{mg}$, RB aqueous solution: $4 \mathrm{~mL}$ ).

Table 1 The Langmuir adsorption parameters of RB and DMY on the Janus HSPHS in solution

\begin{tabular}{|c|c|c|c|c|c|}
\hline RB & $\begin{array}{l}Q_{\max }^{a} \\
\left(\mathrm{~mol} \mathrm{~g}^{-1}\right)\end{array}$ & $K^{a}\left(\mathrm{M}^{-1}\right)$ & DMY & $\begin{array}{l}Q_{\max }^{a} \\
\left(\mathrm{~mol} \mathrm{~g}^{-1}\right)\end{array}$ & $K^{a}\left(\mathbf{M}^{-1}\right)$ \\
\hline HSPHS-1 & 0.68 & 23.29 & HSPHS-2 & 0.14 & 16.10 \\
\hline HSPHS- 2 & 1.43 & 36.28 & HSPHS-3 & 0.11 & 13.64 \\
\hline HSPHS-3 & 3.48 & 22.91 & & & \\
\hline HSPHS-4 & 0.34 & 23.99 & & & \\
\hline
\end{tabular}

${ }^{a}$ The maximum adsorbed amount and the adsorption constant of RB or DMY on the Janus HSPHS were obtained by application of the Langmuir adsorption equation $Q_{\mathrm{e}}=Q_{\max } K C_{\mathrm{e}} /\left(1+K C_{\mathrm{e}}\right)$.

$Q_{\max }$ is the maximum amount of adsorption, and $K$ is the Langmuir adsorption constant. The adsorption parameters of $Q_{\max }$ and $K$ can be easily obtained from Fig. $5 \mathrm{~b}$. It can be seen from Table 1 that the adsorption of RB on the Janus HSPHS provides a $Q_{\max }$ of $0.68,1.43$ and $0.34 \mathrm{~mol} \mathrm{~g}^{-1}$ for HSPHS-1, HSPHS-2 and HSPHS-4, respectively. In this, the anthoid Janus HSPHS with stumpy fibers on the surface was used in the following adsorption and photocatalytic degradation test. It is also found that the Janus HSPHS with a higher degree of sulfonation displayed a much higher adsorption capacity for RB (Fig. 5c), and the $Q_{\max }$ for RB using the anthoid Janus HSPHS with stumpy fibers on the surface increased from 1.43 to $3.48 \mathrm{~mol} \mathrm{~g}^{-1}$ when the sulfonation time increased from $1 \mathrm{~h}$ (HSPHS-2) to $12 \mathrm{~h}$ (HSPHS-3). This may be caused by the electrostatic interaction between the sulfuric acid group and the secondary amino group as well as the $\pi-\pi$ interaction between the polymeric adsorbents and the dye molecule. ${ }^{12,50}$ Besides, the adsorption kinetics test showed that the adsorption rate of RB on HSPHS-3 was very fast and as high as $99.8 \%$ of the $\mathrm{RB}$ was adsorbed within 2 min when the initial $\mathrm{RB}$ concentration was $50 \mathrm{mg} \mathrm{L}^{-1}$, as shown in Fig. $6 \mathrm{a}$.

The interior surface of the Janus HSPHS was hydrophobic PDVB without sulfonic acid groups due to the protection of the

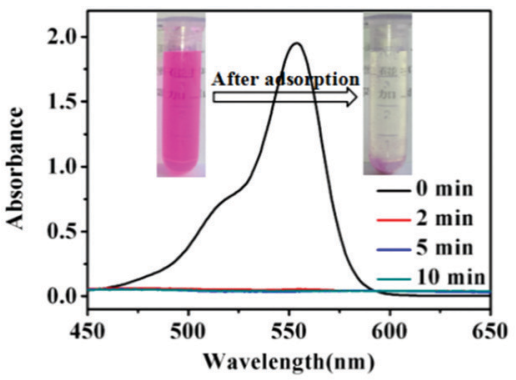

(a)

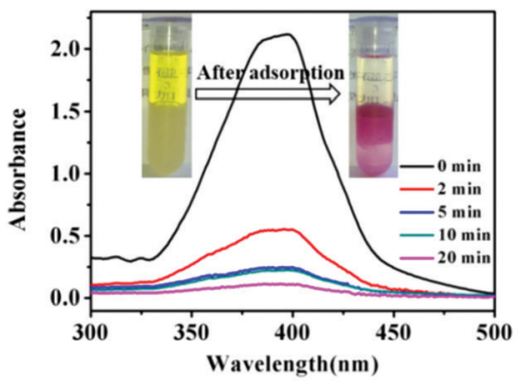

(b)

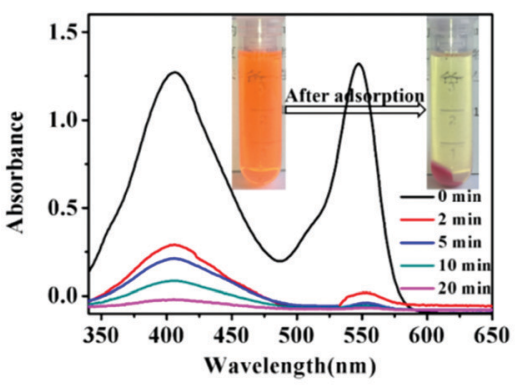

(c)

Fig. 6 The UV-visible spectra of the RB aqueous solution (a) (HSPHS-3: $1 \mathrm{mg}, \mathrm{RB}$ aqueous solution: $50 \mathrm{mg} \mathrm{L}^{-1}, 4 \mathrm{~mL}$ ), DMY solution in hexane (b) (HSPHS-3: $4 \mathrm{mg}$ in $2 \mathrm{~mL}$ water, DMY solution in hexane: $20 \mathrm{mg} \mathrm{L}^{-1}, 2 \mathrm{~mL}$ ), and RB and DMY solution in ethanol (c) (HSPHS-3: $4 \mathrm{mg}$, RB solution in ethanol: $80 \mathrm{mg} \mathrm{L}^{-1}$, DMY solution in ethanol: $20 \mathrm{mg} \mathrm{L}^{-1}, 4 \mathrm{~mL}$ ) adsorbed using the Janus HSPHS-3 as a function of time.

$\mathrm{SiO}_{2}$ cores. Thus, the Janus HSPHS has different affinity on the interior and exterior surfaces, permitting a preferential capture of the hydrophobic species inside the cavity from their aqueous surrounding. Dimethyl yellow (DMY) was selected as a waterinsoluble model compound to evaluate the capture ability of the Janus HSPHS. Upon mixing of the DMY solution in hexane and the Janus HSPHS aqueous suspension, the top hexane phase became less colorful and the bottom aqueous phase turned red due to the combination of captured DMY with sulfonic acid groups, as shown in Fig. 6b. The adsorption isotherms for DMY on the Janus HSPHS are presented in Fig. 7a, showing that the adsorption capacity was decreased with the sulfonation degree. The adsorption of DMY on the Janus HSPHS provides a $Q_{\max }$ of 0.14 and $0.11 \mathrm{~mol} \mathrm{~g}^{-1}$ for HSPHS-2 and HSPHS-3, respectively. The result was in contrary to the adsorption of water-soluble $\mathrm{RB}$, possibly because the interior hydrophobic layer of Janus HSPHS decreased as the sulfonation degree increased, resulting in the reduced capture of water-insoluble DMY. The adsorption rate of DMY on HSPHS 

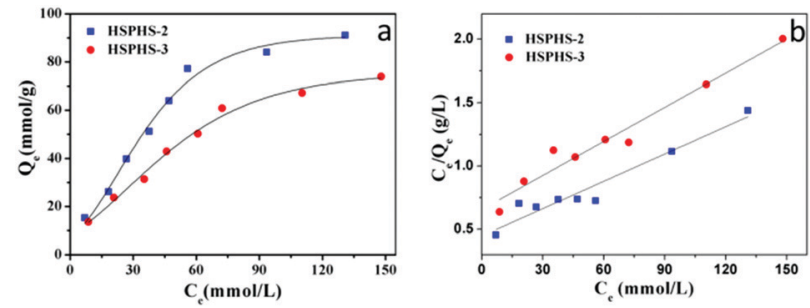

Fig. 7 The adsorption isotherms of DMY (a) and the corresponding linear plots (b) with different Janus HSPHS at room temperature (HSPHS: $1 \mathrm{mg}$ in $1 \mathrm{~mL}$ of water, DMY hexane solution: $1 \mathrm{~mL}$ ).

was very fast and the result demonstrated that as high as $98.2 \%$ of DMY molecules were captured within $20 \mathrm{~min}$ of ultrasonic mixing when the initial DMY concentration was $20 \mathrm{mg} \mathrm{L}^{-1}$, as shown in Fig. $6 b$.

In addition, we also examined the adsorption ability of both water-soluble and water-insoluble molecules at the same time with the Janus HSPHS. The results showed that both RB and DMY dissolve in ethanol and could be adsorbed by HSPHS-3 simultaneously, displaying much less colorful solution after adsorption (Fig. 6c). The adsorption rate of both RB and DMY on the HSPHS was very fast and as high as $98.6 \%$ of RB and $97.1 \%$ of the DMY molecules were adsorbed within $20 \mathrm{~min}$ when the initial concentrations of RB and DMY were 80 and $20 \mathrm{mg} \mathrm{L}^{-1}$, respectively, as shown in Fig. $6 \mathrm{c}$.

\section{Catalytic properties of the HSPHS@TiO}

The Janus HSPHS with sulfonic acid groups make further metal oxide loading feasible, and titania was loaded to explore its application in catalyst systems. Water pollution with dyes is a significant problem to the environment and human health, and photocatalysis with $\mathrm{TiO}_{2}$ containing scaffolds is an attractive approach to degrade the spent dyes. The photocatalytic activities of the samples were determined by photocatalytic degradation decolorization of RB in water under UV irradiation. The photolysis effect of RB without catalysts under UV irradiation was also checked. It was found that the amount of photodegradative RB increased with the initial concentration of $\mathrm{RB}$ when the amount of catalyst was kept constant, and the anatase titania encapsulated HSPHS (HSPHS@TiO ${ }_{2}$-An) showed a much higher catalytic capacity compared with other samples (Fig. S8, ESI†). To evaluate the photocatalytic degradation rate of $\mathrm{RB}$, the time course of the decrease in the concentration of RB was detected under light irradiation of $30 \mathrm{~W}$, and the results are shown in Fig. 8. For the degradation of RB aqueous solution with low concentration (initial RB concentration was $50 \mathrm{mg} \mathrm{L}^{-1}$ ), HSPHS without titania exhibited very low activity (rate constant, $0.0443 \mathrm{~h}^{-1}$ ) as the RB (rate constant, $0.0377 \mathrm{~h}^{-1}$ ) only, and the photodegradation ratio was $15.6 \%$ and $10.9 \%$ for the HSPHS and RB without catalyst respectively under $4 \mathrm{~h}$ of UV irradiation. The HSPHS coated with amorphous titania (HSPHS@TiO ${ }_{2}$-Am) exhibited a decrease of $42.4 \%$ in the photodegradation ratio with a relatively low photocatalytic activity (rate constant, $0.1346 \mathrm{~h}^{-1}$ ) due to the amorphous structure of coated titania. ${ }^{51}$ For HSPHS coated with anatase titania ( $\mathrm{HSPHS} @ \mathrm{TiO}_{2}-\mathrm{An}$ ), the highest photocatalytic
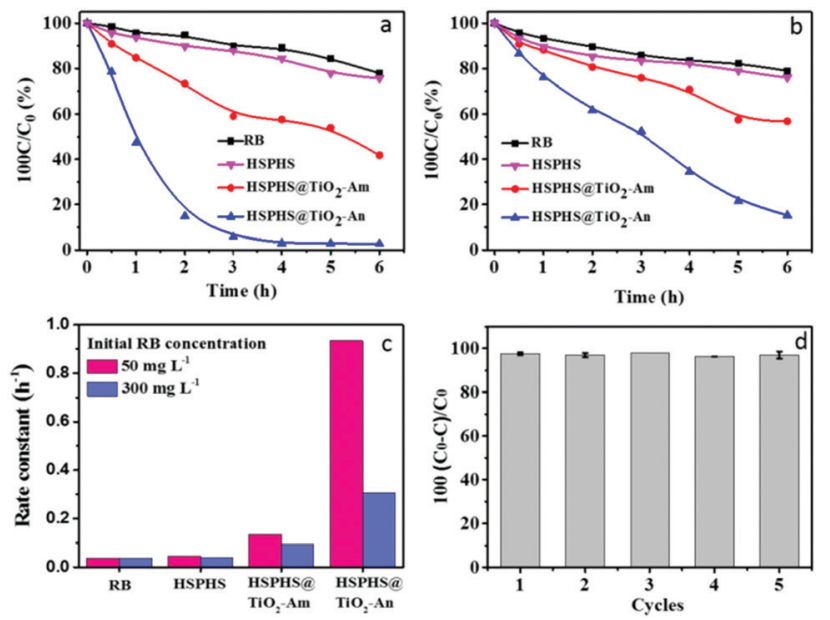

Fig. 8 Time course of the decrease in RB concentration under UV irradiation of $30 \mathrm{~W}$. The initial RB concentration was $50 \mathrm{mg} \mathrm{L}^{-1}$ (a) and $300 \mathrm{mg} \mathrm{L}^{-1}$ (b) (catalyst $1 \mathrm{mg}$, RB solution $4 \mathrm{~mL}$ ). Apparent rate constants (c). Cycling tests of the photocatalytic activity of $\mathrm{HSPHSCTiO}_{2}-\mathrm{An}$ under UV light irradiation (d).

activity is observed with a rate constant of $0.9344 \mathrm{~h}^{-1}$, and the photodegradation ratio of RB was $97.7 \%$ within $4 \mathrm{~h}$ (Fig. $8 \mathrm{a}$ and c).

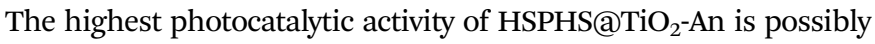
due to the anatase crystallinity of the titania coated on the HSPHS. It's worth mentioning that when the initial concentration of the RB aqueous solution was increased to a fairly high level (300 $\mathrm{mg} \mathrm{L}^{-1}$ ), similar photodegradation of the RB solution was also observed while other parameters were kept constant. The HSPHS@TiO ${ }_{2}$-Am exhibited a decrease of $42.4 \%$ in the photodegradation ratio with a rate constant of $0.0932 \mathrm{~h}^{-1}$. The HSPHS@TiO ${ }_{2}$-An exhibited a photodegradation ratio of $84.7 \%$ for $\mathrm{RB}$, which exhibited a more rapid degradation process (rate constant, $0.3068 \mathrm{~h}^{-1}$ ) than that of the HSPHS@TiO ${ }_{2}$-Am, as shown in Fig. 8b and c.

As a catalyst, in addition to its catalytic efficiency, the recyclable catalytic ability is another important factor to be considered from the perspective of commercial application. Thus, the cycling photodegradation experiment of $\mathrm{RB}$ was performed to confirm the cyclic usage of $\mathrm{HSPHS} \mathrm{TiO}_{2}$-An. The results demonstrated that the $\mathrm{HSPHS} \mathrm{TiO}_{2}$-An possesses a remarkable catalytic efficiency and recyclability. As shown in Fig. 8d, a high catalytic efficiency of $97.7 \%$ is observed for the first cycle and the catalytic efficiency remains $97.0 \%$ with almost no loss of the photocatalytic activity after five catalytic cycles. It is well known that the photodegradation of $\mathrm{TiO}_{2}$ is due to the photogenerated electrons and the holes. The negative conjugation effect shown by the carbons in the aromatic rings with delocalized $\pi$ bonding is beneficial to capture photogenerated electrons. ${ }^{52}$ Therefore, the use of HSPHS as a $\mathrm{TiO}_{2}$ catalyst scaffold exhibited a very high photocatalytic activity. On the other hand, the anatase $\mathrm{TiO}_{2}$ supported on the polymer microspheres was not easily detached due to the coupled action of the sulfonic acid groups, which resulted in the excellent

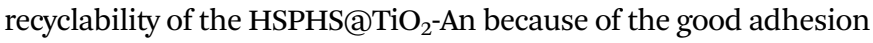
between the titania and HSPHS scaffold. ${ }^{43}$ 


\section{Conclusions}

Janus hollow polymeric hairy microspheres (HSPHS) were fabricated via cationic polymerization of DVB on the surface of $\mathrm{SiO}_{2}$ cores, and then sulfonic acid groups $\left(-\mathrm{SO}_{3} \mathrm{H}\right)$ were introduced onto the surface of the microspheres by sulfonation, followed by the removal of the $\mathrm{SiO}_{2}$ cores via $\mathrm{HF}$ etching. The HSPHS can serve as efficient adsorbents for dye removal from wastewater. The isotherm and kinetics of dye adsorption using the HSPHS as adsorbents were investigated. Hydrophilic dye rhodamine $\mathrm{B}(\mathrm{RB})$ and hydrophobic dye dimethyl yellow (DMY) were used as model compounds. The results showed that $>98 \%$ of $\mathrm{RB}$ or/and DMY could be removed from the surrounding solution within several minutes. The sulfonic acid groups on the HSPHS surface facilitated the further loading of titania, and thus the HSPHS can also serve as catalyst scaffolds for the photocatalytic degradation of RB. Anatase titania loaded HSPHS (HSPHS@TiO ${ }_{2}$-An) demonstrated a remarkable photocatalytic efficiency and recyclability. High photocatalytic activity was observed for $\mathrm{HSPHS}_{\mathrm{N}} \mathrm{TiO}_{2}$-An under light irradiation of $30 \mathrm{~W}$ even when the initial concentration of RB was up to $300 \mathrm{mg} \mathrm{\textrm {L } ^ { - 1 }}$. After five catalytic cycles, the catalytic efficiency remained similar to that of the first cycle with no loss of the photocatalytic activity. Thus, the HSPHS have promising potential in water treatment as efficient adsorbents and catalyst scaffolds.

\section{Conflicts of interest}

There are no conflicts to declare.

\section{Acknowledgements}

The authors are grateful for the financial support provided by the Natural Science Foundation of Ningbo (2016A610049, 2018A610243), the National Natural Science Foundation of China (51773119), the K. C. Wong Magna Fund in Ningbo University, and the Science Technology Innovation Commission of Shenzhen Municipality (GJHZ20180416164817264, JCYJ20180507183036060, JCYJ20170817171930009).

\section{Notes and references}

1 X. Wang, R. Ma, D. Cui, Q. Cao, Z. Shan and Z. Jiao, Sci. Rep., 2017, 7, 14233.

2 G. Bayramoğlu and M. Y. Arica, J. Hazard. Mater., 2007, 144, 449.

3 H. Sadegh, G. A. M. Ali, V. K. Gupta, A. S. H. Makhlouf, R. Shahryari-ghoshekandi, M. N. Nadagouda, M. Sillanpää and E. Megiel, J. Nanostruct. Chem., 2017, 7, 1.

4 M. A. Shannon, P. W. Bohn, M. Elimelech, J. G. Georgiadis, B. J. Marinas and A. M. Mayes, Nature, 2008, 452, 301.

5 B. E. Barragan, C. Costa and M. C. Marquez, Dyes Pigm., 2007, 75, 73.

6 A. B. dos Santos, F. J. Cervantes and J. B. van Lier, Bioresour. Technol., 2007, 98, 2369.
7 C. T. M. J. Frijters, R. H. Vos, G. Scheffer and R. Mulder, Water Res., 2006, 40, 1249.

8 J. Zhang, Q. Shi, C. Zhang, J. Xu, B. Zhai and B. Zhang, Bioresour. Technol., 2008, 99, 8974.

9 V. K. Gupta, R. Jain and S. Varshney, J. Colloid Interface Sci., 2007, 312, 292.

10 F. Liu, Z. Guo, H. Ling, Z. Huang and D. Tang, Microporous Mesoporous Mater., 2016, 227, 104.

11 X. Peng, D. Huang, T. Odoom-Wubah, D. Fu, J. Huang and Q. Qin, J. Colloid Interface Sci., 2014, 430, 272.

12 Y. Ning, Y. Yang, C. Wang, T. Ngai and Z. Tong, Chem. Commun., 2013, 49, 8761.

13 I. Ali, Chem. Rev., 2012, 112, 5073.

14 M. Rafatullah, O. Sulaiman, R. Hashim and A. Ahmad, J. Hazard. Mater., 2009, 170, 969.

15 V. K. Gupta and Suhas, J. Environ. Manage., 2009, 90, 2313.

16 A. Ahmad, M. Rafatullah and M. Danish, Holz Roh-Werkst., 2007, 65, 429.

17 A. Ahmad, M. Rafatullah, O. Sulaiman, M. H. Ibrahim, Y. Y. Chii and B. M. Siddique, Desalination, 2009, 247, 636.

18 B. Pan, B. Pan, W. Zhang, L. Lv, Q. Zhang and S. Zheng, Chem. Eng. J., 2009, 151, 19.

19 E. N. El Qada, S. J. Allen and G. M. Walker, Chem. Eng. J., 2008, 135, 174.

20 E. GilPavas, I. Dobrosz-Gomez and M. A. Gomez-Garcia, Sci. Total Environ, 2019, 651, 551.

21 T. S. Kazeem, S. A. Lateef, S. A. Ganiyu, M. Qamaruddin, A. Tanimu, K. O. Sulaiman, S. M. S. Jillani and K. Alhooshani, J. Cleaner Prod., 2018, 205, 303.

22 S. Sivalingam, T. Kella, M. Maharana and S. Sen, J. Cleaner Prod., 2019, 208, 1241.

23 T. T. N. Phan, A. N. Nikoloski, P. A. Bahri and D. Li, J. Environ. Manage., 2018, 233, 471.

24 S. M. S. Arabi, R. S. Lalehloo, M. R. T. B. Olyai, G. A. M. Ali and H. Sadegh, Phys. E, 2019, 106, 150.

25 L. Wang, W. Liu, T. Wang and J. Ni, Chem. Eng. J., 2013, 225, 153.

26 X. Yang and H. Liu, Chem. - Eur. J., 2018, 24, 13504.

27 K. Zheng, B. Pan, Q. Zhang, W. Zhang, B. Pan, Y. Han, Q. Zhang, D. Wei, Z. Cu and Q. Zhang, Sep. Purif. Technol., 2007, 57, 250.

28 H. P. C. van Kuringen, G. M. Eikelboom, I. K. Shishmanova, D. J. Broer and A. P. H. J. Schenning, Adv. Funct. Mater., 2014, 24, 5045.

29 Y. Xie, T. Wang, X. Liu, K. Zou and W. Deng, Nat. Commun., 2013, 4, 1960.

30 S. Ding and W. Wang, Chem. Soc. Rev., 2013, 42, 548.

31 L. Tan and B. Tan, Chem. Soc. Rev., 2017, 46, 3322.

32 J. Germain, J. Hradil, J. M. J. Frechet and F. Svec, Chem. Mater., 2006, 18, 4430.

33 N. M. Mahmoodi, F. Najafi and A. Neshat, Ind. Crops Prod., 2013, 42, 119.

34 D. D. Maksin, A. B. Nastasovic, A. D. Milutinovic-Nikolic, L. T. Surucic, Z. P. Sandic, R. V. Hercigonja and A. E. Onjia, J. Hazard. Mater., 2012, 209, 99.

35 T. Yao, S. Guo, C. Zeng, C. Wang and L. Zhang, J. Hazard. Mater., 2015, 292, 90. 
36 D. Chen, Y. Liu, Y. Qin, L. Wang, Y. Ma and W. Yang, Chin. J. Chem., 2017, 35, 596.

37 Y. Ning, C. Wang, T. Ngai and Z. Tong, Langmuir, 2013, 29, 5138.

38 Y. Wang, Y. Li, S. Liu and B. Li, Carbohydr. Polym., 2015, 120, 53.

39 Y. Yang, H. Liao, Z. Tong and C. Wang, Compos. Sci. Technol., 2015, 107, 137.

40 M. He, Q. Zhang, X. Zeng, D. Cui, J. Chen, H. Li, J. Wang and Y. Song, Adv. Mater., 2013, 25, 2291.

41 T. Hasell, H. Zhang and A. I. Cooper, Adv. Mater., 2012, 24, 5732.

42 M. Rafatullah, O. Sulaiman, R. Hashim and A. Ahmad, J. Hazard. Mater., 2010, 177, 70.

43 L. Zhang, P. Liu and Z. Su, J. Mater. Sci., 2006, 41, 7218.
44 J. Yu, G. Dai and B. Cheng, J. Phys. Chem. C, 2010, 114, 19378. 45 Y. Chen, Z. Liu, X. Qu, F. Liang and Z. Yang, Chem. - Asian J., 1785, 2016, 11.

46 Y. Tang, L. Liu, X. Wang, D. Jia, W. Xia, Z. Zhao and J. Qiu, J. Power Sources, 2016, 319, 227.

47 K. Lv and Y. Xu, J. Phys. Chem. B, 2006, 110, 6204.

48 K. Lv, X. Guo, X. Wu, Q. Li, W. Ho, M. Li, H. Ye and D. Du, Appl. Catal., B, 2016, 199, 405.

49 K. Lv, J. Yu, K. Deng, J. Sun, Y. Zhao, D. Du and M. Li, J. Hazard. Mater., 2010, 173, 539.

50 B. Pan, Q. Zhang, F. Meng, X. Li, X. Zhang, J. Zheng, W. Zhang, B. Pan and J. Chen, Environ. Sci. Technol., 2005, 39, 3308.

51 J. Yu and B. Wang, Appl. Catal., B, 2010, 94, 295.

52 L. Zhang, H. Gao and Y. Liao, J. Mater. Sci., 2016, 51, 10585. 